\title{
Monitoring of Low Level Arsenic Exposure During Maintenance of Ion Implanters
}

\author{
YAW-HUEI HWANG \\ SHIANG-CHIH CHEN \\ Institute of Occupational Medicine \\ and Industrial Hygiene \\ College of Public Health \\ National Taiwan University \\ Taiwan, Republic of China
}

\begin{abstract}
To delineate potential exposure in ion implanter maintenance, the authors recruited 21 maintenance engineers (exposed group) and 10 computer programmers (controls) at three semiconductor manufacturing facilities. Samples of air, wipes, and urine; used cleaning cloths; and used gloves were collected for the characterization of arsenic exposure. Arsenic levels were very low in environmental samples, but high arsenic levels were found in some wipe samples, used cleaning cloths, and gloves. The average baseline content of urinary arsenic measured for maintenance engineers was $3.6 \mu \mathrm{g} / \mathrm{g}$ creatinine. Maintenance engineers experienced an increase of 1.0-7.8 $\mu \mathrm{g} / \mathrm{g}$ creatinine in urinary arsenic levels during ion implanter maintenance. Results of a mixed-model analysis indicated that urinary arsenic levels were associated significantly with time series $(p=.0001)$, and the extent of association was different among the three facilities $(p=.0226)$. The results of this study indicate that arsenic intake via ingestion, rather than through inhalation, might play a significant role in the elevation of urinary arsenic levels. However, a series of urine samples with self-reference continue to be a good approach for the monitoring of low-level arsenic exposure.
\end{abstract}

ELECTRONICS, ESPECIALLY SEMICONDUCTOR MANUFACTURING, is one of the world's largest industries. Semiconductor manufacturing presents workers with new and often unique sources of exposure to hazardous agents in the "clean" room. ${ }^{1,2}$ Among the various potential occupational hazards in the clean room, arsenic is a site-specific health hazard for maintenance engineers who are regularly assigned the tasks of cleaning ion implanters and disposing of wastes. ${ }^{1-3} \mathrm{~A}$ simplified diagram of the major components of an ion implanter and the surrounding work area appears in Figure 1. Ion implantation is achieved by generating a beam of dopant ions, accelerating the ion beam toward a targeted substrate (i.e., single-crystal silicon), and bombarding selective areas of the substrate surface. ${ }^{2,3}$ The process involves the use of arsine gas or elemental arsenic for the doping of silicon wafers, thus producing a conducting circuit; such a process leaves arsenic residues on equipment, such as an ion implanter, ionsource housings, and a beam line. Maintenance engineers, therefore, may be exposed to airborne arsenic and arsenic residue from maintenance activities and equipment cleaning.

Arsenic is a terrestrial element and is distributed naturally at low or negligible levels in air, water, soil, and food. Environmental contamination resulting from human activities, such as those that occur in industrial processes ${ }^{4}$ is a major health concern. Studies have indicated that soluble forms of arsenic are absorbed readily from the gastrointestinal tract and lungs. Approximately $55-80 \%$ of daily oral intakes or arsenate or arsenite and $40-60 \%$ of inhaled arsenic are excreted in urine..$^{2-8}$ Urinary arsenic, therefore, is a good biomarker for short-term arsenic exposure. On the other 


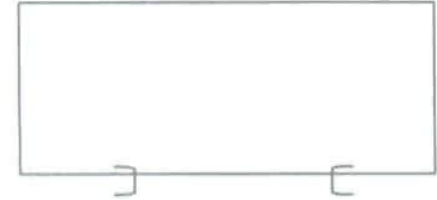

(Hood Window)

\section{Storage Shelf}

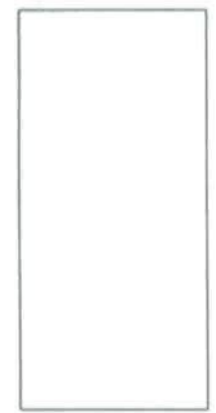

Work Table

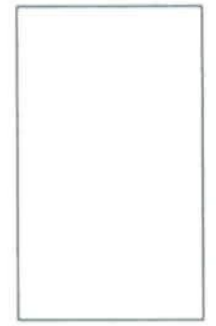

(Passageway)
Ion Implanter

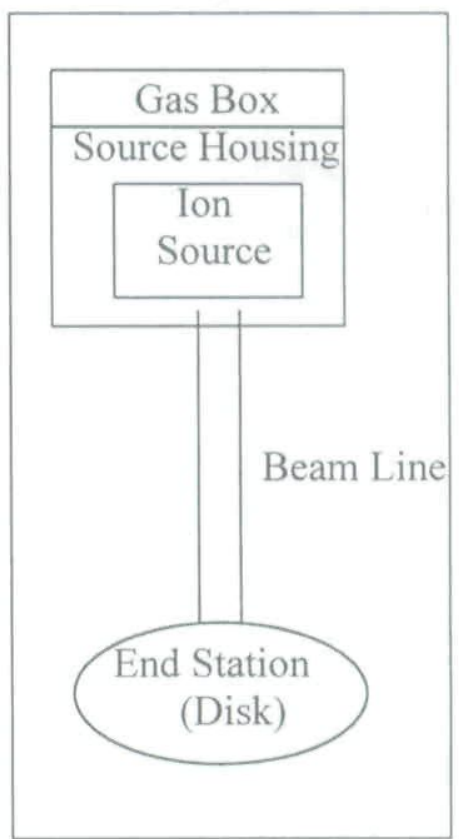

Fig. 1. Simplified diagram of ion implanter and surrounding work area.

hand, arsenic levels in hair and nails are good indicators of long-term accumulated dose inasmuch as arsenic is bound irreversibly with keratin and is no longer part of the body's pool of biologically active arsenic. ${ }^{9}$ Epidemiological studies have shown that arsenic is associated with cancers of the lung, skin, liver, bladder, and kidney. ${ }^{10-15}$ In addition, long-term exposure to arsenic may lead to diseases associated with the nervous, cardiovascular, reproductive, and respiratory symptoms, and it may be associated with skin abnormalities, including patches of hyper- and hypopigmentation, as well as with multiple hyperkeratotic "warts." ${ }^{16}$

In a previous study, ${ }^{1}$ Ungers and Jones demonstrated that airborne arsenic levels were very low in the ion implanter area, except when maintenance work at the beam line area was conducted. In another study, the authors showed that the mean hair arsenic of maintenance engineers regularly assigned to fabrication areas was slightly - but not significantly - higher than that of administration controls. Although there is a paucity of data that verify the perceived risk, arsenic exposure of maintenance engineers around ion implanters remains a concern. We suspected that such occupational exposure might result from direct interaction with processing equipment, from the handling of process chemicals, or via contact with process wastes. To identify the possible arsenic exposure among engineers, we measured envi- ronmental samples and a series of urine samples as an alternative to delineate the potential arsenic exposure during ion implanter maintenance.

\section{Materials and Method}

In this study, we assessed arsenic exposure at the work environments of three ion implanters in two fabrication companies. In all of the ion implanters, elemental arsenic was the ion source for implantation in the manufacturing process. During the site-specific walk through, we learned that primary maintenance was conducted twice a year. Tooling or components dismounted from the ion implanter were cleaned in the exhaust hoods, whereas ion source housing-which was not removed from the ion implanter-was cleaned on-site by scrubbing with a cleaning cloth and isopropyl alcohol, anhydrous alcohol, or hydrogen peroxide. At the time of the study, ventilation, personal protection, and other recommended health and safety practices were already in place.

Each ion implanter area was investigated for $1 \mathrm{wk}$. Maintenance engineers $(n=21)$ on duty comprised the exposed group, and 10 designated computer programmers who worked in the office served as the controls. Given that arsenic contamination may be in the forms of aerosol and/or residues on the surface of work areas, 
air samples, wipe samples, used cleaning cloths, used gloves, and urine samples were obtained for exposure assessment. Personal and area air samples were obtained for both arsenic and arsine determination. Area samples were collected at the work sites (i.e., source housing, beam line, end station, hoods, nearby area of ion implanter, and administration office). Personal samples were obtained from all recruited maintenance engineers.

Airborne arsenic was collected on $37-\mathrm{mm}$ mixedcellulose ester filters (pore size $=0.8 \mu \mathrm{m}$ ), and arsine was collected on solid absorbent tubes equipped with a preset mixed-cellulose ester filter for removal of arsenic particulates. ${ }^{17,18}$ Air arsenic samples were digested in a microwave with a mixture of nitric, perchloric, and sulfuric acids in the proportion of $3: 1: 1$ by volume. The digested solution was then analyzed for arsenic by an hydride-generation atomic absorption spectrometer (HGAAS [Perkin Elmer FIAS 400, Perkin Elmer AAS 3110]) with a detection limit of $0.4 \mu \mathrm{g} / \mathrm{l}^{16}$ Air arsine samples were first desorbed with $0.01 \mathrm{M}$ nitric acid in an ultrasonic cleaner for $30 \mathrm{~min}$. Following centrifugation, the supernatant was then analyzed for arsine with a graphite furnace atomic absorption spectrometer (GFAAS [Perkin Elmer AAS 5100], detection limit $=2.3 \mu \mathrm{g} / \mathrm{l}) .{ }^{18}$

To characterize arsenic deposition, we collected wipe samples with moistened no. 1 Advantec 90-mmdiameter filter paper obtained from a predefined $10 \mathrm{x}$ $10-\mathrm{cm}^{2}$ hot spot of each ion implanter and from the nearby work areas. Collected samples were enclosed in zipped bags and stored in a refrigerator at $4{ }^{\circ} \mathrm{C}$ until laboratory analysis. The cleaning cloths that personnel used to scrub arsenic residues from the ion implanters and from the tooling or dismounted components were collected as bulk samples, as were maintenance engineer's polyvinyl chloride used gloves. The pretreatment of wipe samples and the subsequent analysis for arsenic mirrored the procedure we used for arsenic samples. A central $5 \times 5-\mathrm{cm}^{2}$ portion of each cleaning cloth sample was cut and desorbed with $0.01 \mathrm{M}$ nitric acid and ultrasonic cleaner for $30 \mathrm{~min}$. A $1-\mathrm{ml}$ aliquot of the mixed solution was then digested with digesting acid and was analyzed for arsenic by HGAAS (i.e., as was done for arsenic samples). We used a similar method and procedure to analyze arsenic-contaminated gloves, which we cut into $0.5 \times 1.5-\mathrm{cm}^{2}$ pieces.

Participating maintenance engineers provided firstvoid morning urine samples on each day of the study week. The first samples were provided on Monday morning, which followed a 2-d break from work; therefore, these samples were used as individual self-baselines. Computer programmers (controls) also provided urine samples as described for the engineers. Urine samples were collected in 500-ml bottles, acidified with nitric acid, and then stored at $4{ }^{\circ} \mathrm{C}$ for further analysis. We used the Hitachi special automatic analyzer (Model 7450) to measure urinary creatinine with a colorimetric method. ${ }^{19}$ If a sample contained an abnormally low or high level of creatinine (i.e., $<0.5 \mathrm{~g} / \mathrm{l}$ or $>3.0 \mathrm{~g} /$, respectively) indicative of a very dilute or dense urine specimen, we excluded the urinary arsenic result from analysis because the arsenic concentration might have been spuriously low or high. ${ }^{20}$ Each urine sample was pretreated with $3 \%$ sodium borohydride and analyzed directly with HGAAS. With this method, we were able to determine if any or all of the following four major metabolites of inorganic arsenic were present in urine: (1) $\mathrm{As}^{3+}$, (2) $\mathrm{As}^{5+}$, (3) monomethylarsonic acid, and (4) dimethylarsinic acid. ${ }^{21}$ The detection limit of this direct method was $0.1 \mu \mathrm{g} /$.

Field blanks were obtained for each batch of environmental and biological samples. Different levels of spikes were performed for quality control of arsenic determination. In addition, we applied a standard addition method to correct urine matrix effects in the establishment of the calibration curve for urinary arsenic analysis. A detailed description of the quality assurance/quality control process can be found elsewhere. ${ }^{22}$ In addition, we collected information about the subjects via questionnaires that included queries about demographics, behaviors, work history, workrelated syndrome and symptoms, general environmental conditions related to potential arsenic exposure, consumption of seafood, and drinking water, among others. The Wilcoxon Rank Sums test and a mixedmodel analysis were applied and run on the Statistical Analysis System for the statistical analysis of urinary arsenic levels with relevant leading factors. ${ }^{23}$

\section{Results}

Among 21 maintenance engineers recruited in the present study, 10 were from facility A, 5 were from facility B, and 6 were from facility C. All engineers were male, and their average age was 29.0 y (geometric standard deviation $[G S D]=3.2 \mathrm{y}$ ). The mean duration of work history in the clean room was $21.1 \mathrm{mo}$ (GSD = $16.9 \mathrm{mo}$ ), and each engineer spent 4-9 hr daily in the ion implanter area. The average age and duration of work history for the 10 computer programmers (controls) were 31.1 y $(G S D=2.5 \mathrm{y})$ and $25.5 \mathrm{mo}(G S D=$ $13.6 \mathrm{mo})$, respectively. None of the programmers had worked in the clean room.

Airborne arsenic levels in samples taken from 8 areas when the cleaning process was performed (e.g., dismounting major parts of equipment, scrubbing and cleaning the removed parts, cleaning the ion implanter) are shown in Table 1. Of the total 93 air samples, arsenic was undetectable in 46 samples. Four samples collected from the inside hood area and 1 sample from the source housing area presented the highest levels $35-560 \mu \mathrm{g} / \mathrm{m}^{3}$. In no other samples did the airborne arsenic level exceed the recommended occupational exposure limit of $10 \mu \mathrm{g} / \mathrm{m}^{3} .{ }^{24}$ Geometric means of air arsenic levels in the 8 measured areas were rather low, except for the mean level of $4.62 \mu \mathrm{g} / \mathrm{m}^{3} \quad(G S D=14.3)$ in the inside hood areas (Table 1). The second highest average level was found in the outside hood areas $(0.72$ $\left.\mu \mathrm{g} / \mathrm{m}^{3}\right)$, followed by the source housing areas $(0.67$ $\left.\mu \mathrm{g} / \mathrm{m}^{3}\right)$; no arsenic was detected in the office area. Airborne arsenic varied widely with respect to space and 
Table 1.-Concentrations of Airborne Arsenic and Arsine During Ion Implanter Maintenance

\begin{tabular}{|c|c|c|c|c|c|c|}
\hline Sample types & Chemical & $\begin{array}{c}\text { Sample } \\
\text { no. }\end{array}$ & $\begin{array}{l}\text { No. of samples with } \\
\text { concentration > DL* }\end{array}$ & GMt & GSD & Range $\neq$ \\
\hline \multicolumn{7}{|l|}{ Sample area } \\
\hline \multirow[t]{2}{*}{ Housing source } & Arsenic & 26 & 16 & 0.67 & 6.5 & $0.12-440$ \\
\hline & Arsine & 10 & 7 & 0.04 & 4.0 & $0.01-0.49$ \\
\hline \multirow[t]{2}{*}{ Inside hood } & Arsenic & 19 & 14 & 4.62 & 14.3 & $0.24-560$ \\
\hline & Arsine & 13 & 9 & 0.04 & 3.2 & $0.02-0.41$ \\
\hline \multirow[t]{2}{*}{ Outside hood } & Arsenic & 7 & 5 & 0.72 & 3.5 & $0.20-4.45$ \\
\hline & Arsine & 3 & 0 & \multicolumn{2}{|c|}{ ND } & ND \\
\hline \multirow[t]{2}{*}{ Beam line } & Arsenic & 9 & 4 & 0.46 & 2.2 & $0.19-0.90$ \\
\hline & Arsine & 5 & 3 & 0.03 & 1.9 & $0.02-0.06$ \\
\hline \multirow[t]{2}{*}{ End station } & Arsenic & 9 & 4 & 0.13 & 4.6 & $0.05-1.30$ \\
\hline & Arsine & 4 & 0 & \multicolumn{2}{|c|}{ ND } & ND \\
\hline \multirow[t]{2}{*}{ Work table } & Arsenic & 4 & 1 & 0.32 & - & 0.32 \\
\hline & Arsine & $\neq$ & - & - & - & - \\
\hline \multirow{2}{*}{ Passageway } & Arsenic & 8 & 3 & 0.20 & 3.0 & $0.09-0.72$ \\
\hline & Arsine & 6 & 3 & 0.04 & 2.0 & $0.02-0.08$ \\
\hline \multirow[t]{2}{*}{ Office } & Arsenic & 11 & 0 & \multicolumn{2}{|c|}{ ND } & ND \\
\hline & Arsine & 4 & 0 & \multicolumn{2}{|c|}{ ND } & ND \\
\hline \multirow[t]{2}{*}{ Subtotal } & Arsenic & 93 & 47 & 0.92 & 9.2 & $0.05-560$ \\
\hline & Arsine & 45 & 22 & 0.04 & 2.9 & $0.01-0.49$ \\
\hline \multicolumn{7}{|l|}{ Personal sample } \\
\hline Maintenance & Arsenic & 31 & 11 & 1.66 & 2.2 & $0.50-7.00$ \\
\hline engineers & Arsine & 35 & 15 & 0.07 & 4.3 & $0.01-1.66$ \\
\hline \multicolumn{7}{|c|}{$\begin{array}{l}\text { Notes: } \mathrm{DL}=\text { detection limit, } G M=\text { geometric mean, } G S D=\text { geom } \\
\text { detectable. Arsenic reported in } \mu \mathrm{g} / \mathrm{m}^{3} \text {, and arsine reported in ppb. } \\
\text { *Arsenic } \mathrm{DL}=0.01 \mu \mathrm{g} / \mathrm{m}^{3} \text {, and arsine } \mathrm{DL}=0.01 \mathrm{ppb} \text {. } \\
\text { tOnly samples of concentrations that exceeded the DL were included. } \\
\text { fData were not available. }\end{array}$} \\
\hline
\end{tabular}

Table 2.-Arsenic Loading on Work Surfaces, Cleaning Cloths, and Gloves

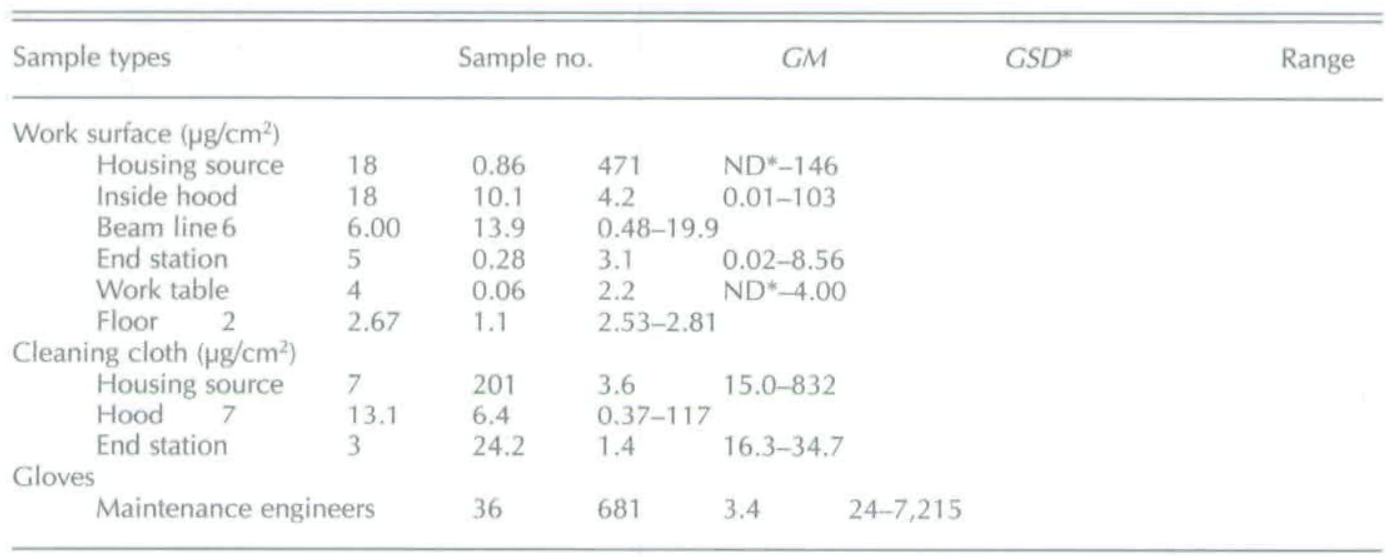

Notes: $G M=$ geometric mean, $G S D=$ geometric standard deviation, and ND = not detectable.

*Detection limit of wipe sample for arsenic was $0.0005 \mu \mathrm{g} / \mathrm{cm}^{2}$, which was used in the calculation of GM and GSD for the value under detection limit.

time (Table 1). Although some maintenance activities might have produced high exposure levels of arsenic, during most of the maintenance periods there was little arsenic in air. Results of personal airborne arsenic exposure showed a similar trend to that described. Twenty of 31 samples were below the detection limit of 0.01 $\mu \mathrm{g} / \mathrm{m}^{3}$. The geometric mean arsenic level of the remaining 11 samples was $1.66 \mu \mathrm{g} / \mathrm{m}^{3}(G S D=2.2)$. The high- est arsenic level of $7 \mu \mathrm{g} / \mathrm{m}^{3}$ occurred in facility A and was experienced by an engineer who was dismounting and scrubbing major parts of the ion implanter for $4 \mathrm{~h}$.

Arsine concentrations during maintenance work are also shown in Table 1. Twenty-two of 45 area samples and 15 of 35 personal samples had detectable arsine levels, but all values were well below the occupational exposure limit of $50 \mathrm{ppb}$ recommended by the Ameri- 
can Conference of Governmental Industrial Hygienists. ${ }^{20}$ No arsine was detected in the areas outside the hood, at the end station, and in the office. The highest personal arsine exposure of $1.66 \mathrm{ppm}$ - greater than all the measures taken from area samples-was found while a maintenance engineer of factory A cleaned the removed parts with isopropyl alcohol during the 2 nd day of maintenance work.

Arsenic levels on the surfaces of work areas, used cleaning cloths, and used gloves are shown in Table 2. A total of 53 wipe samples were taken from various work surfaces following maintenance activities. Dust arsenic loading on work surfaces varied from nondetectable to $146 \mu \mathrm{g} / \mathrm{cm}^{2}$; the highest levels were found at some parts of the source housing areas. Geometric means of arsenic levels were significantly higher in the hood and beam line areas than all the other areas (Wilcoxon Rank Sums test, $p=.0024$ ). Seventeen samples were taken from used cleaning cloths, and the highest arsenic levels were found in cloths collected from the source housing areas (geometric mean $[G M]=$ $201 \mu \mathrm{g} / \mathrm{cm}^{2}, G S D=3.6$ ). In addition, gloves used by maintenance engineers for dismounting the major parts of the ion implanter and cleaning parts had high-level arsenic residues that ranged from $24 \mu \mathrm{g} /$ piece to 7,215 $\mu \mathrm{g} /$ piece $(G M=681 \mu \mathrm{g} /$ piece, $G S D=3.4 \mu \mathrm{g} /$ piece $)$.

A total of 98 urine samples were collected during the maintenance week from participating maintenance engineers and computer programmers. The average urinary arsenic level for the 10 programmers was $3.8 \mu \mathrm{g} / \mathrm{g}$ creatinine (Table 3 ). The average urinary arsenic level measured for maintenance engineers on the first day was $3.6 \mu \mathrm{g} / \mathrm{g}$ creatinine-a value not statistically different from that of the nonexposed group.

The fluctuation of urinary arsenic levels among the maintenance engineers during the week of ion implanter maintenance is shown in Table 3. The average urinary arsenic levels for engineers at facility A increased steadily from $3.7 \mu \mathrm{g} / \mathrm{g}$ creatinine on the $1 \mathrm{st}$ day and reached the highest average level of $8.5 \mu \mathrm{g} / \mathrm{g}$ creatinine on the 5th morning, after which levels declined slowly during the days that followed. The average urinary arsenic levels, however, ranged from 3.4 $\mu \mathrm{g} / \mathrm{g}$ creatinine to $4.8 \mu \mathrm{g} / \mathrm{g}$ creatinine for engineers at facilities B and C. There was no apparent change found during the week of study, except that an average of 8.0 $\mu \mathrm{g} / \mathrm{g}$ creatinine was found on the 6th day of study for engineers from facility $B$.

The results of the mixed-model analysis are summarized as follows:

$$
\begin{aligned}
& \text { Urinary arsenic levels, } \mu \mathrm{g} / \mathrm{g} \text { creatinine } \\
& =\text { Facilities } \\
& + \text { Time Series } \\
& + \text { Time Series * Facilities } \\
& \begin{array}{l}
(p=.0681) \\
(p=.0001) \\
(p=.0226) .
\end{array}
\end{aligned}
$$

Urinary arsenic levels measured for engineers were associated significantly with time series and differed among the three facilities. No effects of airborne arsenic, gaseous arsine, and arsenic loading on arsenic levels

\begin{tabular}{|c|c|c|c|c|c|c|c|c|}
\hline & \multirow{2}{*}{$\begin{array}{c}\text { Computer } \\
\text { programmers* }\end{array}$} & \multicolumn{7}{|c|}{ Maintenance engineers } \\
\hline & & Day $1+$ & Day $2+$ & Day 3† & Day 4t & Day 5t & Day $6+$ & Day $7+$ \\
\hline \multicolumn{9}{|l|}{ Facility A } \\
\hline$n$ & 4 & 7 & 7 & 7 & 7 & 4 & 2 & 2 \\
\hline $\bar{x}$ & 4.0 & 3.7 & 3.7 & 3.8 & $5.5 \S$ & $8.5 / /$ & $5.9 \S$ & $6.1 \S$ \\
\hline Rangef & $2.5-4.6$ & $2.8-4.7$ & $2.3-5.8$ & $2.5-5.2$ & $3.0-8.3$ & $5.1-10.6$ & $4.9-6.8$ & $4.3-8.0$ \\
\hline \multicolumn{9}{|l|}{ Facility B } \\
\hline$n$ & 4 & 3 & 4 & 4 & 4 & 5 & 5 & 5 \\
\hline $\bar{x}$ & 4.4 & 4.0 & 3.9 & 3.6 & 4.2 & 4.3 & 4.8 & 4.4 \\
\hline Range‡ & $3.5-5.7$ & $2.8-5.6$ & $2.4-6.6$ & $2.6-5.6$ & $3.0-7.0$ & $3.0-6.4$ & $2.6-7.1$ & $3.3-6.6$ \\
\hline \multicolumn{9}{|l|}{ Facility C } \\
\hline$n$ & 3 & 6 & 6 & 5 & 2 & - & 2 & - \\
\hline $\bar{x}$ & 2.7 & 3.4 & 3.7 & 3.5 & 4.4 & - & 8.0 & - \\
\hline Range $\neq$ & $2.2-3.1$ & $2.0-6.0$ & $1.8-8.6$ & $1.3-6.6$ & $1.6-7.3$ & & $1.9-14.2$ & \\
\hline \multicolumn{9}{|l|}{ Total } \\
\hline$n$ & 11 & 16 & 17 & 16 & 13 & 9 & 9 & 7 \\
\hline $\bar{x}$ & 3.8 & 3.6 & 3.8 & 3.7 & 4.9 & 6.2 & 5.8 & 4.9 \\
\hline Rangef & $2.2-5.7$ & $2.0-6.0$ & $1.8-8.6$ & $1.3-6.6$ & $1.6-8.3$ & $3.0-10.6$ & $1.9-14.2$ & $3.3-8.0$ \\
\hline
\end{tabular}
were observed. Neither was there an apparent effect of the use of a supplied-air respirator. Nevertheless, we

Table 3.-Arsenic Levels of the First-Voided Morning Urine among Maintenance Engineers During the Week of Ion Implanter Maintenance $(\mu \mathrm{g} / \mathrm{g}$ creatinine)

*Computer programmers were the nonexposed group.

tThe day on which urine samples were collected. Day 1 indicates the first day of the 1 -wk maintenance work, at which time the engineers had just returned to work after a 2-d weekend hiatus. Therefore, the urinary arsenic level of Day 1 for each engineer was used as self-baseline in the Wilcoxon Rank Sums test in comparison with the urinary arsenic levels of each of the other work days.

$\ddagger$ Range of urinary arsenic levels.

$\S p<.05$.

$\| p<.005$ 


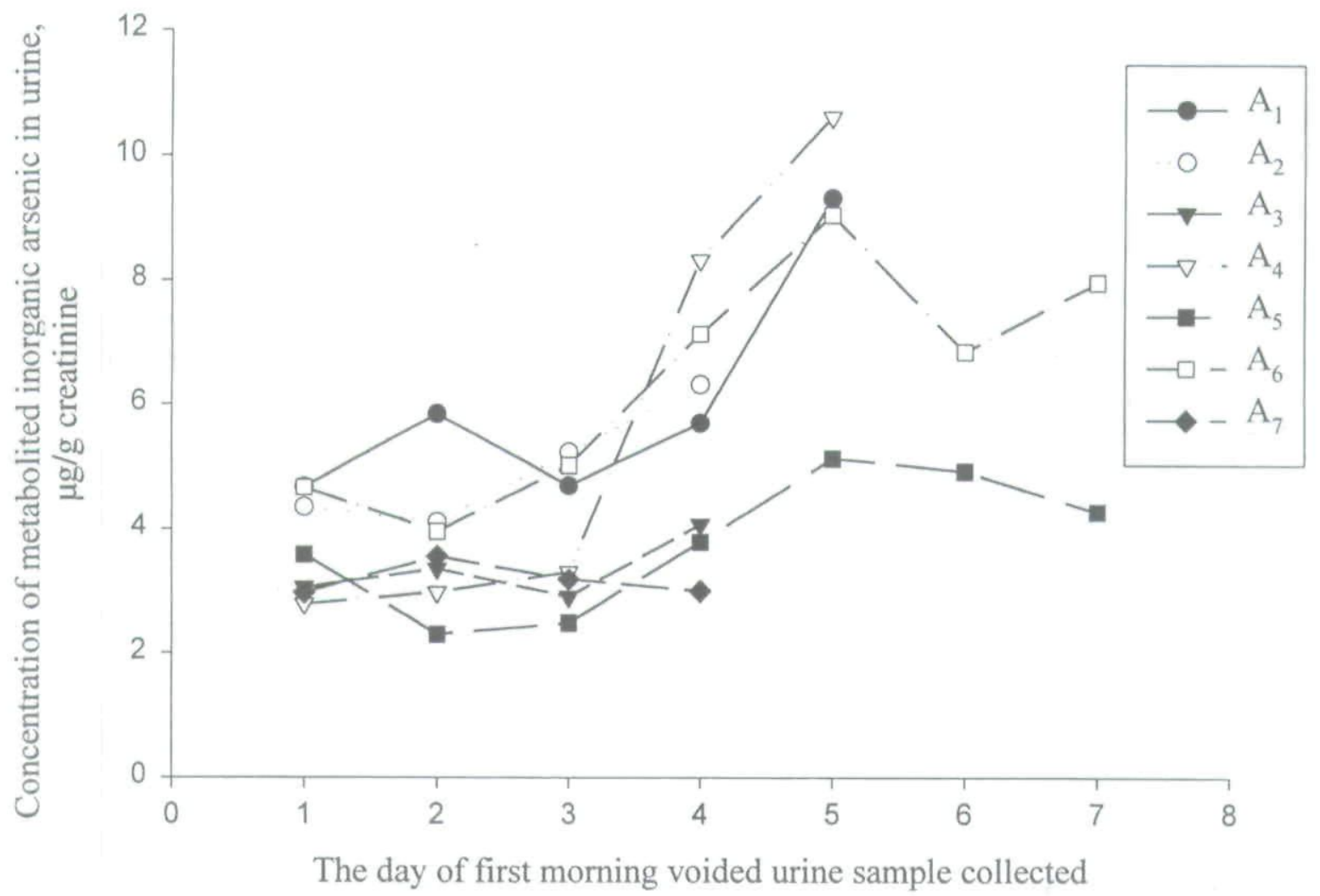

Fig. 2. Urinary arsenic levels measured for 7 maintenance engineers in facility A during the week of ion implanter maintenance.

found that most engineers at facility A did not wear fullface-piece respirators with supplied air at work as required, but, instead, wore dust-preventing masks. In contrast, all maintenance engineers at facilities B and C had a high rate of compliance with this requirement.

To clearly delineate the fluctuation of urinary arsenic levels in the maintenance week, we plotted individual arsenic levels of 7 maintenance engineers at facility A. Their urine samples were available for analysis for at least 4 successive days during the study period. In Figure 2 it is clearly shown that during the first $3 \mathrm{~d}$ most urinary arsenic concentrations leveled at approximately 3-4 $\mu \mathrm{g} / \mathrm{g}$ creatinine. The levels of engineers $\mathrm{A}_{4}$ and $\mathrm{A}_{6}$ climbed to $10.6 \mu \mathrm{g} / \mathrm{g}$ creatinine and $9 \mu \mathrm{g} / \mathrm{g}$ creatinine, respectively; the levels for engineers $A_{1}$ and $A_{2}$ were elevated only moderately. No changes were observed for engineers $A_{3}$ and $A_{7}$. Levels for engineer $A_{5}$ decreased from $3.6 \mu \mathrm{g} / \mathrm{g}$ creatinine on day 1 to $2.5 \mu \mathrm{g} / \mathrm{g}$ creatinine on day 3 ; thereafter, on day 5 , the arsenic concentration elevated to $5.1 \mu \mathrm{g} / \mathrm{g}$ creatinine.

\section{Discussion}

In this study, we conducted an arsenic-exposure assessment by directly measuring arsenic levels in the work environment and by determining the body burden in maintenance engineers. We measured subject-specific arsenic contamination sources in each section of the ion implanter areas to determine their potential influence on each individual's arsenic intake. We based the biological indication of the study subjects' arsenic body burden on consecutive, first-void morning urine samples to yield an accurate estimate. Given that the halflife of most absorbed arsenic species in the human body is approximately $1-3 \mathrm{~d}, 5,25,26$ our study design was appropriate and allowed for evaluation of low-level occupational arsenic exposure in ion implanter maintenance engineers in the semiconductor industry.

Arsenic exposures other than work-related sources were also of concern in our study. Some undefined fraction of arsenic could arise from daily diet (i.e., drinking water and food), whereas arsenic exposure through inhalation and skin contact might be alternative pathways of environmental arsenic uptake. However, given that self-comparison was a component of this study, we should not have had to measure other common environmental arsenic exposures of different pathways. Rather, we administered a questionnaire to facilitate identification of any unusual exposure to arsenic during the study period (e.g., use of arsenic pesticides and lacquer painting, intake of arsenic-containing Chinese medicine). We confirmed that there was no unusual arsenic exposure in the study subjects. We therefore attributed elevated urinary arsenic levels in the study period to exposure at the ion implanter maintenance areas.

Results of the mix-model analysis clearly reflected a daily elevation of urinary arsenic levels among maintenance engineers, even though the increase was minimal. In fact, urinary arsenic levels for most maintenance 
engineers increased significantly during the latter days of the week, compared with their baseline levels on day 1. In general, these maintenance engineers experienced an increase in urinary arsenic of 1.0-7.8 $\mu \mathrm{g} / \mathrm{g}$ creatinine. Given that the half-life of arsenic is approximately $1-3 d$, the elevations in our study provided evidence that levels of excreted urinary arsenic increased with time-largely the result of exposure during the first $2 \mathrm{~d}$ associated with maintenance work that involved dismounting, scrubbing, and cleaning processes.

Wipe samples that contained high arsenic levels were taken from the work surfaces of source housings and inside hood areas. This finding was not surprising; we expected that most arsenic levels originated from maintenance activities. High arsenic residues were also present for the bulk samples of used cleaning cloths and used gloves. These results implied that there were important alternative sources of arsenic exposureother than airborne arsenic particulates - to which the maintenance engineers were exposed. Perhaps the route of arsenic exposure during ion implanter maintenance might occur primarily through ingestion, rather than inhalation. This route was very likely because contact with any arsenic-containing dust might lead to inadvertent ingestion, thus resulting in elevated urinary arsenic levels. This scenario can be demonstrated further if we assume that elevated urinary arsenic levels could be attributed entirely to the arsenic uptake via inhalation and if we compare the expected airborne arsenic concentrations derived from data available from the current study. For example, the average increase in urinary arsenic levels of the maintenance engineers of facility A, after their ion implanter maintenance work, was $4.4 \mu \mathrm{g} / \mathrm{g}$ creatinine (range $=1.0-7.8 \mu \mathrm{g} / \mathrm{g}$ creatinine); this increase accounted for approximately 12.1 $\mu \mathrm{g}$ of extra arsenic excreted in urine each day, given that urinary creatinine level normally averages $1.96 \mathrm{~g} / \mathrm{l}$ and urinary excretion averages $1.4 \mathrm{l} / \mathrm{d} .{ }^{27}$ If we attribute this $12.1-\mu \mathrm{g} / \mathrm{d}$ increase in urinary arsenic to work-related exposure via inhalation, we could conservatively estimate the time-weighted average air arsenic concentrations to be as high as $5.3-8.0 \mu \mathrm{g} / \mathrm{m}^{3}$-assuming a tidal volume of $0.5 \mathrm{I}$, a breathing frequency of $18 / \mathrm{min}$, a 7 $\mathrm{hr}$ workshift during which personal respiratory protection equipment was not worn, and a $40-60 \%$ excretion of inhaled arsenic in urine. ${ }^{7,8}$ In our study, however, only 11 of 31 air samples contained detectable arsenic concentrations $\left(G M=1.66 \mu \mathrm{g} / \mathrm{m}^{3}\right.$ [Table 2]). Even if the maintenance engineers had worked in areas that had arsenic levels of $5.3-8.0 \mu \mathrm{g} / \mathrm{m}^{3}$, they may not have had high arsenic levels in urine (i.e., $12.1 \mu \mathrm{g} / \mathrm{d}$ ) because they might have worn respirators or masks for exposure prevention during most work hours. The aforementioned estimation implies that arsenic exposure for maintenance engineers in the work environment may occur through important alternative pathways other than inhalation.

The results of the mix-model analysis also showed that wearing an supplied-air respiratory did not have an effect on urinary arsenic levels. For example, $A_{5}$ and $A_{7}$ (Fig. 2) were the only two engineers who complied with the requirement that supplied-air respirators be worn during maintenance work. Although urinary arsenic levels of engineer $A_{7}$ did not increase significantly, the levels of engineer $A_{5}$ did increase-most obviously during the latter part of the work week. The same situation was observed in facility $C$ for 1 engineer who had an exceptionally high urinary arsenic level of $14.2 \mu \mathrm{g} / \mathrm{g}$ creatinine (Table 3 ). These results imply that sporadic contact with arsenic and uptake via ingestion may play a significant role in elevated urinary arsenic levels.

Given the feasibility and practicality, urine analysis in series, by workshifts, is an efficient means by which low-level arsenic exposure can be monitored in the types of facilities we studied. Sample preparation of urine samples is easier and less expensive than other biological measurements. Also, given the short half-life of arsenic in the human body, a series of urine arsenic monitoring with self-reference becomes a helpful tool in the measurement of recent low-level occupational arsenic exposure. In addition, a first-void morning urine sample can be substituted for the 24-hr urine sample because there is typically an estimated ratio of 1.4 between arsenic concentration in the first-void morning urine and total amount of excreted arsenic in 24-hr urine samples ${ }^{8}$ In addition, collection of the first-void morning urine sample could eliminate the awkwardness and messiness inherent with 24-hr urine collection; as well, this approach is more feasible and practicable in the workplace. Therefore, measurement of urinary arsenic levels after a series of workshifts, which reflects the comprehensive arsenic exposure that contributes to the body burden, is an appropriate monitor of potential occupational exposure to low levels of arsenic. On the basis of our observations, we recommend that an increase in urinary arsenic of $4-5 \mu \mathrm{g} / \mathrm{g}$ creatinine be used as a checkpoint for further improvements in working environments, personal protection, and personal hygiene.

Two important occupational hygiene issues have been raised in this study. First, low-level arsine was identified in the ion implanter areas during maintenance periods. This finding is of great concern inasmuch as the protection principle and measures of gaseous arsine are different from the airborne arsenic particulate. The manufacture engineers indicated that no gaseous arsine was used during the wafer fabrication process. Perhaps arsine is formed through the reactions between element arsenic and cleaning agents used in the cleaning process (e.g., isopropyl alcohol, anhydrous alcohol, hydrogen peroxide). These agents, which were placed on cleaning cloths, were used widely during the ion implanter cleaning process. Investigators should conduct further studies to clarify the sources and formation process of arsine and to provide appropriate guidelines about arsine prevention in the workplace. Another concern is that sporadic high-level particulate dispersion may occur during the cleaning of the ion implanter areas (Table 1). In the clean room, a stringent air-quality standard of Class I is applied (i.e., 1 particulate $/ \mathrm{ft}^{3}$ for particulates $>0.5 \mu \mathrm{m}$ in diameter). Therefore, personnel should pay more attention to housekeeping 
activities in the ion implanter area during maintenance-not only for the prevention of arsenic exposure, but for product quality control.

The average arsenic level in the ion implanter areas was usually low in our study, implying that there was no evidence of, or imminent adverse health threat to, workers in the studied work environments. Nonetheless, elevated excretion of arsenic remained demonstrable; therefore, researchers must work to further reduce arsenic exposure, particularly because the International Agency for Research on Cancer has recognized arsenic sa a human carcinogen. ${ }^{28}$ We must eliminate any unnecessary exposure to reduce the risk of potential adverse health effects. Given that arsenic exposures may arise from airborne arsenic and/or dusty arsenic in the field, the supervisors and maintenance engineers must be more cautious during maintenance work to effectively eliminate inadvertent contact and ingestion of arsenic-containing material. Use of a series of urine samples for monitoring between workshifts would facilities their efforts with efficiency.

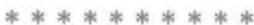

The authors thank Dr. J. D. Wang and Dr. F. C. Sung for their helpful comments and suggestions.

The authors gratefully acknowledge the National Science Council of Executive Yuan, Taiwan, Republic of China, for financial support (contract no. NSC 87-2314-B-002-348).

Submitted for publication December 8, 1998; revised; accepted for publication July 18, 1999.

Requests for reprints should be sent to Dr. Yaw-Huei Hwang, Institute of Occupational Medicine and Industrial Hygiene, College of Public Health, National Taiwan University, Room 1453, No. 1, Sec. 1, Jen-Ai Rd., Taipei, Taiwan, ROC.

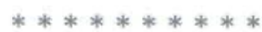

\section{References}

1. Unger LJ, Jones $\mathrm{H}$. Industrial hygiene and control technology assessment of ion implantation operations. Am Ind Hyg Assoc I 1986; 47(10):607-14.

2. Harrison M. Semiconductor manufacturing hazards. In: Sullivan JB Jr, Krieger GR (Eds). Hazardous Materials Toxicology, Clinical Principles of Environmental Health. Baltimore, MD: Williams and Wilkins, 1992; pp 472-504.

3. Peyster A, Silvers JA. Arsenic levels in hair of workers in a semiconductor fabrication facility. Am Ind Hyg Assoc J 1995; 56 377-86.

4. United States Environmental Protection Agency (EPA). Arsenic. In: Intermedia Priority Pollutant Guidance Documents. Washing. ton, DC: EPA, Office of Pesticides and Toxic Substances; 1982.

5. Buchet IP, Lauwerys R, Roels H. Urinary excretion of inorganic arsenic and its metabolites after repeated ingestion of sodium metaarsenite by volunteers. Int Arch Occup Environ Health 1981:48:111-18.

6. Johnson LR, Farmer JG. Use of human metabolic studies and urinary arsenic speciation in assessing arsenic exposure. Bull Environ Contam Toxicol 1991; 46:53-61.
7. Pinto SS, Varner MO, Nelson KW, et al. Arsenic trioxide absorption and excretion in industry. J Occup Med 1976; 18:677-80.

8. Vahter M, Friberg L, Rahnster B, et al. Airborne arsenic and urinary excretion of metabolites of inorganic arsenic among smelter workers. Int Arch Occup Environ Health 1986; 57:79-91.

9. Vahter M, Marafante $E$. In vivo methylation and detoxification of arsenic. Royal Soc Chem 1988; 66:105-19.

10. Enterline PE, Marsh GM, Esmen NA, et al. Some effects of cigarette smoking, arsenic, and $\mathrm{SO}^{2}$ on mortality among U.S. copper smelter workers. J Occup Med 1987; 29(10):831-38.

11. Smith $A H$, Hopenhayn-Rich C. Bates $M N$, et al. Cancer risks from arsenic in drinking water. Environ Health Perspect 1992; 97 259-67.

12. Roat JW, Wald A, Mendelow $\mathrm{H}$, et al. Hepatic angiosarcoma associated with short-term arsenic ingestion. Am I Med 1982; 73:933-36.

13. Zaldivar R, Prumes L, Ghai GL. Arsenic dose in patients with cutaneous carcinomata and hepatic haemangio-endothelioma after environmental and occupational exposure. Arch Toxicol $1981 ; 47: 145-54$

14. Chen CJ, Kuo TL, Wu MM. Arsenic and cancers. Lancet 1998; $\mathrm{i}: 414-15$.

15. Wu MM, Kuo TL, Hwang $\mathrm{YH}$, et al. Dose-response relationship between arsenic concentration in well water and mortality from cancers and vascular disease. Am J Epidemiol 1989; 130: $1123-32$.

16. Agency for Toxic Substances and Disease Registry (ATSDR). Toxicological Profile for Arsenic. US DHHS PHS. Washington, DC: ATSDR, 1993; contract no. 205-88-0608.

17. National Institute for Occupational Safety and Health (NIOSH) Manual of Analytical Methods: Method No. 6001-Arsine. Cincinnati, OH: NIOSH, 1994; 4th ed.

18. National Institute for Occupational Safety and Health (NIOSH). Manual of Analytical Methods: Method No. 6001-Arsine. Cincinnati, OH: NIOSH, 1994; 4th ed.

19. Henry RJ. Clinical Chemistry: Principles and Technique. New York: Harper \& Row, 1965; 3rd ed.

20. American conference of Governmental Industrial Hygienists (ACGIH). Threshold limit values (TLVs) for chemical substances and physical agents and biological exposure indices (BEIs), 1995-1996. Cincinnati, OH: ACGIH, 1995.

21. Norin $H$, Vahter $M$. A rapid method for the selective analysis of total urinary metabolites of inorganic arsenic. Scand J Work Environ Health $1981 ; 7: 38-44$.

22. Chen SC. Workers' Exposure to Arsenic in the Maintenance of Ion Implanters in Semiconductor Fabrication Facilities (Master's Thesis). Taipei, Taiwan: National Taiwan University, 1998 (in Chinese).

23. SAS. SAS/STAT User's Guide. Cary, NC: SAS Institute, 1998; ver 6.12.

24. National Institute for Occupational Safety and Health (NIOSH). Pocket Guide to Chemical Hazards, Cincinnati, OH: NIOSH, 1990.

25. Crecelieus EA. Changes in the chemical speciation of arsenic following ingestion by man. Environ Health Perspect 1977; 19 $147-50$.

26. Tam GKH, Charbonneau SM, Bryce F, et al. Metabolism of inorganic arsenic $\left({ }^{74} \mathrm{As}\right)$ in humans following oral ingestion. Toxicol Appl Pharmacol 1979; 50:319-22.

27. Guyton AC. Human Physiology and Mechanisms of Disease. Philadelphia, PA: Saunders, 1997; 5th ed.

28. International Agency for Research on Cancer (IARC). Evaluation of Carcinogenic Risks to Humans (suppl 7). Lyon, France: IARC. 1987; pp 100-06. 
Copyright of Archives of Environmental Health is the property of Heldref Publications and its content may not be copied or emailed to multiple sites or posted to a listserv without the copyright holder's express written permission. However, users may print, download, or email articles for individual use. 